\title{
Mulemba
}

Revista Angolana de Ciências Sociais

5 (10) | 2015

Angola 40 anos de independência: memória, identidades, cidadania e desenvolvimento

\section{As Ciências Sociais e a mudança ambiental global. Desafios para o Desenvolvimento Sustentável em África}

The Social Sciences and global environmental change. Challenges for Sustainable Development in Africa

\section{Nelson Lourenço e Carlos Russo Machado}

\section{(2) OpenEdition}

Journals

\section{Edição electrónica}

URL: http://journals.openedition.org/mulemba/2079

DOI: 10.4000/mulemba.2079

ISSN: 2520-0305

\section{Editora}

Edições Pedago

Edição impressa

Data de publição: 1 novembro 2015

Paginação: 289-321

ISSN: 2182-6471

\section{Refêrencia eletrónica}

Nelson Lourenço e Carlos Russo Machado, «As Ciências Sociais e a mudança ambiental global.

Desafios para o Desenvolvimento Sustentável em África», Mulemba [Online], 5 (10) | 2015, posto online no dia 12 outubro 2018, consultado o 26 janeiro 2021. URL: http://journals.openedition.org/mulemba/ 2079 ; DOI: https://doi.org/10.4000/mulemba.2079 


\title{
As Ciências Sociais e a mudança ambiental global. Desafios para o Desen- volvimento Sustentável em África*
}

\author{
Nelson Lourenço ${ }^{* *}$ e Carlos Russo Machado ${ }^{* * *}$
}

\begin{abstract}
Resumo: As actividades humanas estão a transformar o Sistema Terra com impactos significativos sobre o ambiente ao nível local, regional e global. As alterações climáticas e a perda de biodiversidade dificultam a melhoria do bem-estar humano e a redução da pobreza.

A nível global é essencial compreender de que forma as pressões sobre os ecossistemas constituem um risco para o funcionamento do Sistema Terra, em geral, e da sociedade, em particular. Em África, a promoção da sustentabilidade e a procura de melhor qualidade de vida para as populações enfrenta desafios de particular importância, nomeadamente os que estão relacionados com o acesso a água potável, ar limpo e alimentos; a adaptação dos sistemas de governança para promoção da sustentabilidade; a gestão de áreas urbanas; a redução da pobreza e a criação de rendimento.

Nesta conferência, propõe-se um novo quadro teórico e analítico multidisciplinar para o estudo de questões críticas para o desenvolvimento e a sustentabilidade global: segurança alimentar, segurança hídrica, segurança energética, segurança na saúde e segurança humana. Este novo quadro conceptual tem de produzir e integrar novos conhecimentos em áreas como: governança e limites e limiares de mudança; uso sustentável do capital natural e conservação da biodiversidade; estilos de vida, ética e valores; implicações económicas das mudanças tecnológicas e sociais associadas à transição para economias com baixa intensidade de carbono.

Considerando a escala e impactos das actividades humanas, as estratégias de sustentabilidade têm forçosamente de integrar as perspectivas e conhecimentos das ciências sociais na análise da mudança ambiental global e na definição de estratégias e políticas de desenvolvimento.
\end{abstract}

* Comunicação apresentada no Campus Universitário de Kamama, em Luanda, no dia 11 de Abril de 2014, Sexta-feira, 14hoo, no âmbito das actividades da Trienal UAN Humanidades - I Congresso 2014, «Conferência Plenária r: Humanidades, Globalização e Desenvolvimento», uma organização das Faculdades de Direito, Economia, Ciências Sociais e Letras da Universidade Agostinho Neto (uan), Luanda, de 11 a 18 de Abril de 2014.

** Professor Catedrático, Instituto de Direito e Segurança da Faculdade de Direito da Universidade Nova de Lisboa (UNL).

*** Docente da Universidade Atlântica e Comité Nacional do IGBP/Global Change - Programa Internacional para a Geosfera e Biosfera - Mudança Global. 
Palavras-chave: Sistema Terra, mudança global, desenvolvimento, sustentabilidade, análise integrada, governança, África.

\section{O Sistema Terra e a mudança global}

As interacções das mudanças ambientais com as sociedades humanas têm uma história longa e complexa, tendo conduzido à criação de novos quadros teóricos e conceptuais para o seu estudo. A investigação destas questões faz apelo, necessariamente, a multidisciplinariedade, à integração de conhecimentos de diferentes disciplinas científicas e à análise sistémica. Este tipo de abordagem, que contrasta com métodos mais tradicionais que tendem a analisar os sistemas integrados de acordo com os seus componentes, obriga a um esforço de conceptualização de novas metodologias de trabalho, e de criação de equipas pluridisciplinares que integrem investigadores de diferentes domínios científicos das ciências sociais e das ciências naturais.

Tradicionalmente o estudo do funcionamento do Planeta foi abordado a partir da divisão clássica das suas componentes em litosfera, hidrosfera, atmosfera e biosfera, em grande medida de forma disciplinar, na qual as variáveis e os seus efeitos são analisados isoladamente. Contudo, embora cada uma destas esferas represente grandes componentes do Planeta, elas sobrepõem-se de forma tão significativa, que não é possível considerar que funcionam de forma isolada umas das outras.

A contribuição da análise sistémica para o estudo das Ciências da Terra é fundamental, na medida em que vem introduzir a necessidade de observar, analisar e medir as complexas interacções destas componentes, entendidas enquanto subsistemas abertos de um sistema mais amplo: o Sistema Terra. Só deste modo, as repostas aos problemas ambientais podem ser desenhadas tendo em conta o leque alargado de consequências inerentes a um sistema complexo e interactivo.

A análise sistémica e a sua aplicação ao estudo do ambiente não são novas. Sendo certo que o conceito de Ecossistema foi desenvolvido na década de 1930 (TANSLEY 1935; Odum 1953), também é verdade que os exemplos de aplicação da análise sistémica ao ambiente (por exemplo, o estudo da geomorfologia fluvial) referem-se apenas a uma parte do sistema de funcionamento da Terra. Nas últimas décadas foram feitos progressos consideráveis na compreensão das interacções que moldam o Sistema Terra (Goudie 2000; WAINWRIGHT 
2009; Rockströм et al., 2009), nomeadamente ao nível do desenvolvimento de um quadro conceptual que abrange o Sistema Terra como um todo e da compreensão das dinâmicas naturais do sistema contribuindo, deste modo, para fornecer uma base robusta para avaliar os efeitos e consequências das mudanças produzidas pela sociedade neste sistema.

De acordo com Steffen et al. (2004), a expressão Sistema Terra refere-se às interacções dos processos físicos, biológicos e químicos do Planeta. Este sistema abrange a terra, os oceanos, a atmosfera e os pólos. Inclui os ciclos naturais do planeta (do carbono, da água, do azoto, do fósforo, do enxofre e outros ciclos) e processos do interior da Terra. A vida é uma parte integrante do Sistema Terra, uma vez que influencia os ciclos do carbono, do azoto, da água, do oxigénio e muitos outros ciclos e processos. Naturalmente, o sistema inclui a sociedade humana. Os sistemas sociais e económicos estão incorporados no Sistema Terra. Em muitos casos, os sistemas humanos são actualmente os principais motores da mudança no Sistema Terra.

O Sistema Terra deve ser, assim, entendido como o conjunto de interacções dos processos físicos, químicos, biológicos e sociais, que no conjunto transportam e transformam materiais e energia, proporcionando assim as condições necessárias à vida no Planeta Terra. Os seres humanos não podem ser entendidos como uma força externa que perturba o sistema natural. Pelo contrário, os seres humanos são uma parte integrante e interactiva do Sistema Terra.

Mudança Global refere-se às mudanças, de escala planetária, que afectam o Sistema Terra. Mais precisamente, a expressão «Mudança Global» abrange (STEFFEN et al., 2004): mudanças à escala planetária na circulação atmosférica, na circulação oceânica, no clima, no ciclo do carbono, no ciclo do azoto, no ciclo da água e em outros ciclos, na extensão do gelo marinho, no nível do mar, nas cadeias alimentares, na biodiversidade, na poluição, na saúde, nas populações de peixes entre outras. A civilização é actualmente um grande motor da mudança global, pelo que esta expressão inclui igualmente mudanças na população, na economia, no uso de recursos, na energia, no desenvolvimento, nos transportes, na comunicação, na ocupação e uso do solo, na urbanização, nos processos de globalização.

De acordo com o IGBP - Programa Internacional para o estudo da Geosfera e Biosfera (IGBP 2006), a Mudança Global é, assim, um conceito bastante mais abrangente do que as suas manifestações, mais divulgadas: Aquecimento Global ou Alterações Climáticas. Na 
verdade, as mudanças na concentração de gases na Atmosfera, as mudanças de uso do solo, as mudanças na diversidade biológica, as dinâmicas demográficas (crescimento da população e movimentos migratórios), estão a conduzir outras modificações que afectam o funcionamento e a estrutura dos ecossistemas e que condicionam as formas como a sociedade tem de gerir, mitigar e adaptar-se a essas mudanças (STEFFEN et al. 2004; TURNER II, 2009; ROCKSTRÖM et al., 2009).

Deste modo, o fenómeno da Mudança Global é presentemente entendido como o conjunto das diversas mudanças (ambientais, sociais, económicas, culturais, institucionais) de origem natural e humana, que afecta, à escala planetária, os processos físicos, químicos, biológicos e socioeconómicos e o modo como esses processos interagem local e regionalmente (Johnston et al., 2002; OldField e STEFFEN 2004; IGBP 2006). Trata-se, assim, de um conjunto de processos cujas causas e consequências se manifestam em diferentes escalas espaciais e temporais e que são ampliadas pelas tendências recentes (sociais, culturais, políticas e económicas) do processo de globalização (ADGER et al., 2005).

Para além disso, a Mudança Global não pode ser analisada em termos de simples relações de causa e efeito. As mudanças induzidas pela sociedade podem originar vários efeitos que se desenvolvem de forma complexa em cascata através do Sistema Terra. Esses efeitos interagem uns com os outros e com mudanças, à escala local e regional, tomando padrões multidimensionais que são difíceis de compreender e ainda mais difíceis de prever. Assim, os impactos das actividades humanas e as consequências da degradação ambiental para as actividades humanas não podem ser considerados em separado dado que se encontram profundamente relacionadas. Estas interacções do Sistema Terra caracterizam-se pela grande incerteza e complexidade, tornando difícil a tarefa de gerir as mudanças. Deste modo, ao mesmo tempo que modificam os sistemas naturais, os sistemas sociais mudam, porque têm de se adaptar a essas mudanças (LouRENço et al., 1999).

\section{Antropocénico: A crescente influência das ac- tividades humanas na mudança ambiental global}

Até muito recentemente na história da Terra, os seres humanos e as suas actividades foram uma força insignificante nas dinâmicas do 
Sistema Terra. As mudanças ambientais induzidas pela sociedade tiveram impactos muito localizados e, por vezes, de nível regional. Estas características da pegada ecológica humana sobre o Sistema Terra mudaram dramaticamente com a Revolução Industrial do final do século xviII. O surgimento de sistemas energéticos à base de combustíveis fósseis produziu mudanças na capacidade humana de transformar o planeta. A tecnologia aumentou a capacidade da sociedade para extrair e consumir recursos e produzir resíduos, tendo facilitado um enorme aumento da população global. O resultado ficou expresso no aumento mundial da procura de recursos naturais, incluindo bancos pesqueiros, materiais inertes, água doce e solos com grande produtividade agrícolas, e nas consequências ambientais da produção e do consumo para o funcionamento do Sistema Terra.

As actividades humanas estão a influenciar significativamente o ambiente da Terra em muitos aspectos. Para além das emissões de gases com efeito estufa e das alterações climáticas é possível identificar actualmente importantes mudanças, que ultrapassam a variabilidade natural, na superfície terrestre, nos oceanos, nas áreas costeiras e na atmosfera da Terra e na diversidade biológica. Uma dimensão destaca-se pela sua notoriedade. A segunda metade do século xx assistiu à mais rápida transformação do relacionamento dos seres humanos com o mundo natural na história da humanidade (STEFFEn et al., 2004).

Nos últimos 50 anos, a estrutura e o funcionamento de praticamente todos os ecossistemas da Terra foram significativamente transformados em resultado da acção humana. Estas mudanças têm sido especialmente rápidas nos países em vias de desenvolvimento. É este enquadramento que leva alguns autores a sugerirem que estamos numa nova época geológica: o Antropocénico. ${ }^{1}$ Esta é uma palavra criada por Eugene Stoermer (que desenvolveu a sua investigação na área da Ecologia) e popularizada, desde 2000, por Paul Crutzen (Prémio Nobel da Química de 1995), para designar a nova época geológica. Esta época teria começado no final do século xviII, com a Revolução Industrial (refira-se que a máquina a vapor, patenteada, em 1784, por James Watt, lançou um período de enorme desenvolvimento tecnológico, que possibilitou o surgimento

1 Esta é uma designação polémica que ainda não foi adoptada na nomenclatura oficial geológica. Espera-se o seu reconhecimento oficial em 2016 pela IUGS International Union of Geological Sciences e, ao mesmo tempo, a declaração do fim do Holocénico. 
de novas e poderosas formas de manipulação do ambiente), período a partir do qual as actividades dos seres humanos (Homo sapiens) começaram a alterar substancialmente o Sistema Terra: superfície terrestre, oceanos, atmosfera e ciclos dos nutrientes.

Após a Revolução Industrial na Europa, a intensidade de manipulação do ambiente evoluiu de forma relativamente lenta, durante um século e meio antes da fase de grande aceleração que se verificou após 1950. O consumo estimulado pelo crescimento económico e tecnologia ultrapassou a população enquanto principal motor de mudança (SYvitski 2012).

A Mudança Global representa, assim, uma profunda alteração na relação entre os seres humanos e o resto da Natureza, estando a conduzir o Planeta para terra incognita. Crescimento da população e crescimento económico são as forças motrizes das sociedades modernas: urbanizadas, industrializadas, terciarizadas, consumidoras de recursos naturais e produtoras de resíduos. Num mundo globalizado, as actividades humanas são, cada vez mais, uma força dominante de indução da mudança. Neste contexto, a Mudança Global é um processo que está a produzir pressões crescentes na sociedade, tornando a sustentabilidade, o maior desafio para a sociedade do século XXI.

\section{Desenvolvimento sustentável}

Nos anos imediatamente após à Segunda Guerra Mundial, economistas e políticos dos países desenvolvidos viam o crescimento económico, assente na tecnologia e orientada para o consumo, como o caminho para um futuro global de prosperidade e segurança para todos. Para ser justo, alguns concebiam uma diferença entre crescimento económico e desenvolvimento! Mas só alguns reflectiam sobre se este conceito poderia ser conciliado com as realidades ambientais (LOURENÇO 2001; LOURENÇO 2005).

No final dos anos sessenta, foi ficando claro que a tecnologia e o crescimento económico nem sempre eram compatíveis ou inevitavelmente positivos. Embora não se possa negar as melhorias materiais significativas nas vidas de milhões de pessoas, principalmente nos países ocidentais, o crescimento económico, tal como estava a ser implementado nos países desenvolvidos ou nos países em desenvolvimento, produziu efeitos colaterais potencialmente trágicos sob a forma de poluição e esgotamento de recursos. 
Em 1972, o Clube de Roma, divulgou um relatório, Limites do Crescimento, no qual foi sugerido que se os padrões económicos continuassem, o mundo iria enfrentar em breve um desastre ecológico. Começou então a perceber-se que os limites de tolerância ambiental para interferência humana estavam a ser atingidos, e que se o modelo de crescimento económico e desenvolvimento não fosse modificado o futuro do mundo estaria em causa. Outra conclusão importante foi a de que o problema do esgotamento de recursos e da degradação do ambiente era um problema global.

Em 1983, a Organização das Nações Unidas convocou uma comissão de alto nível, a Comissão Mundial sobre Meio Ambiente e Desenvolvimento (WCED), vulgarmente conhecida como Comissão Brundtland. Em 1987, no seu relatório final, O Nosso Futuro Comum, salientou a necessidade de crescimento económico e de estratégias de desenvolvimento em todos os países que reconhecessem os limites da capacidade dos ecossistemas se regenerarem e absorverem os resíduos.

Foi a Comissão Brundtland que popularizou a expressão desenvolvimento sustentável e reconheceu a aceleração da interdependência ecológica entre as nações. A wCED enfatizou a ligação entre o desenvolvimento económico e as questões ambientais, e identificou a erradicação da pobreza como um requisito necessário e fundamental para o desenvolvimento ambientalmente sustentável.

O desenvolvimento sustentável é, assim, visto como a base para um verdadeiro equilíbrio entre o crescimento económico e os valores ambientais, assentando na definição de problemas orientados para a sociedade, incluindo não só a dimensão da eficiência económica, mas também os da justiça social e da regulação política.

Foi uma contribuição positiva enquanto «[...] réplica à afirmação comum dos anos 1970 que o crescimento económico zero, era desejável e até mesmo inevitável, especialmente no longo prazo, dadas as limitações ambientais e de recursos [...]» (PAELKE 1999: 244). Apresentou a forma como as restrições ao crescimento económico podem, em certos contextos, aumentar, em vez de reduzir, os danos ambientais. Na verdade, o crescimento económico tanto produz custos ambientais, como proporciona oportunidades ambientais.

Em contraste com a teoria da modernização, a ideia de desenvolvimento sustentável «[...] enfatiza a diversidade de caminhos para o desenvolvimento, em função das especificidades culturais ou políticas, bem como dos pontos de partida ecológicos [...]» (BECKER 1997: 
10). Em todo o caso, o conceito de desenvolvimento sustentável não pode evitar a ambiguidade inerente à palavra desenvolvimento, que significa um modelo de sociedade, ou seja, a generalização dos padrões das sociedades construídas pelos países ocidentais.

Vinte e sete anos após ter sido publicamente proposto pela Comissão Brundtland, é hoje consensual que a ideia de desenvolvimento sustentável representa um salto teórico e conceptual positivo e indiscutível e uma valiosa contribuição para a análise do crescimento económico e do desenvolvimento, na medida em que:

- Introduz a ideia de uma forte ligação entre crescimento económico e recursos naturais/ambiente;

- Introduz a ideia da relação complexa entre crescimento e ambiente, chamando a atenção para a necessidade de se ter em mente as ideias de sustentabilidade ambiental, sustentabilidade económica e sustentabilidade social, e a necessidade de conciliação dos conflitos entre essas diferentes dimensões;

- Ao contrário da Declaração do Clube de Roma, afirma que o crescimento económico «zero» pode ser tão prejudicial para o meio ambiente como o crescimento económico descontrolado;

- Introduz a ideia de que a luta contra a pobreza e pela justiça social e pela qualidade de vida são objectivos essenciais, a fim de garantir a sustentabilidade nas suas dimensões ambientais, económicos e sociais;

- Afirma a ideia, ao contrário do que era defendido pelas teorias clássicas de desenvolvimento, que a sustentabilidade não é um processo linear e não pode ser calibrada por um modelo de desenvolvimento único e universal.

\section{Sustentabilidade ambiental: equidade social e segurança humana}

Equidade, segurança e ambiente constituem elementos-chave da definição de desenvolvimento sustentável, exigindo uma abordagem integrada e interactiva que permita a compreensão da complexa relação entre sociedade e natureza no que diz respeito aos direitos humanos, e assumindo que o ambiente é uma dimensão essencial do futuro da espécie humana.

É abundante a literatura científica que apresenta em evidências empíricas que mostram como a degradação do ambiente ou 
o esgotamento dos recursos afectam as pessoas numa sociedade e entre países de formas diferentes, criando e reforçando novas formas de discriminação social e económica. As consequências da pobreza são enormes e desiguais. Muitos estudos mostram que as regiões económicas e socialmente mais desfavorecidas e com maiores taxas de desemprego, apresentam maior facilidade de acolhimento de indústrias poluentes.

O triângulo ambiente/pobreza/saúde ajuda a ilustrar como o ambiente pode estar associado com a discriminação social e a iniquidade. ${ }^{2}$ Para a Organização Mundial de Saúde (oms) um pré-requisito para uma boa saúde é o acesso à água potável, alimentos, roupas, habitação e saneamento. Abaixo de um certo nível desses factores, é impossível manter a saúde. Para uma grande parte da população mundial, este é o problema mais relevante.

Também ao nível da sustentabilidade dos recursos hídricos se verifica uma certa conflitualidade com a sustentabilidade económica. $\mathrm{O}$ fornecimento de água potável e de serviços de saneamento básico são questões de gestão que aumentam as preocupações sobre a iniquidade da prestação deste tipo de serviços, particularmente nos países em desenvolvimento. Apesar da importância da água, mais de 783 milhões de pessoas em todo o mundo ainda não têm acesso a fontes melhoradas de água, e um volume ainda maior de população não tem acesso a água potável de forma segura e consistente.

Na verdade, grandes volumes de água potável são perdidos desnecessariamente, tornando-se urgente aumentar a eficiência no uso da água, no sentido de diminuir as perdas, os custos de captação distribuição e tratamento da água e de reduzir a necessidade de desenvolver novas fontes e expandir as infra-estruturas de distribuição destes recursos. A unEsCo estima que cerca de metade da água de sistemas de abastecimento de água potável nos países em desenvolvimento é perdida devido a fugas, ligações clandestinas e vandalismo (UNESCO 2009). Esta situação priva os operadores dos sistemas de abastecimento de água, dos recursos económicos que poderiam usar para manter e expandir o serviço. Em 1999, o Banco Mundial estimava que seria necessário investir, em todo o mundo, cerca de 600 mil milhões

2 É importante notar que iniquidade não é sinónimo de desigualdade. As desigualdades sociais contam como iniquidades apenas quando são: evitáveis, desnecessárias e injustas. 
de dólares para reparar e melhorar os sistemas de distribuição de água. Num estudo mais recente, o McKinsey Global Institute estima que será necessário investir em todo o mundo 12 biliões de dólares, até 2030, de modo a garantir de forma segura o acesso à água e saneamento a toda a população mundial (MCKINSEY 2013: 75).

É também um facto que os fenómenos extremos, como as cheias, representam um encargo excessivo para os mais pobres. Embora por vezes se considere que a meteorologia é a única coisa que trata todas as pessoas igualmente, torna-se cada vez mais claro que a população mais economicamente desfavorecida é igualmente a mais vulnerável às consequências de longo prazo das alterações climáticas, nomeadamente na relação saúde/ambiente.

Os bens e serviços dos ecossistemas contribuem significativamente para o emprego e para a actividade económica global, pelo que as mudanças nos bens e serviços dos ecossistemas influenciam as componentes do bem-estar humano. A diminuição do bem-estar humano tende a aumentar a dependência e a pressão sobre os ecossistemas, contribuindo para uma competição sobre os recursos naturais que pode ser geradora de tensões e conflitos que põem em causa a segurança.

É, assim, necessário olhar mais profundamente as relações entre ambiente, economia e sociedade, a fim de ter uma ideia mais clara e precisa sobre as relações entre mudança ambiental, degradação ambiental, escassez de recursos renováveis e a segurança humana.

Em 1987, a Comissão Mundial sobre Meio Ambiente e Desenvolvimento enfatizou que o stress ambiental poderia ser tanto uma causa, como um resultado de conflitos. A Academia Nacional de Ciências dos EUA (1991) reconheceu que as alterações climáticas podem ser, no futuro, um importante catalisador de instabilidade, especialmente em regiões onde possam constituir ameaças à segurança.

O conceito de segurança foi durante muito tempo interpretado de forma muito restritiva: segurança do território relativamente a agressões externas; protecção dos interesses nacionais na política externa; segurança global contra a ameaça de um holocausto nuclear. Este conceito tem sido mais relacionado com os Estados-nação do que com as pessoas.

Contudo, em 1994, a UNDP propôs um conceito de segurança humana com um âmbito mais abrangente, incluindo sete categorias: 
- Segurança económica (assegurar rendimentos básicos aos indivíduos);

- Segurança alimentar (assegurar acesso físico e económico à alimentação);

- Segurança na saúde (assegurar a protecção mínima contra doenças e estilos de vida não saudáveis);

- Segurança ambiental (acesso a água potável, ar limpo e a um sistema terrestre não degradado);

- Segurança pessoal (segurança dos indivíduos contra ameaças e violência física exercida por outros indivíduos ou Estados);

- Segurança da comunidade (segurança contra «limpezas» étnicas: genocídio, migrações forçadas, etc.);

- Segurança política (protecção dos direitos humanos e da liberdade).

Deste modo, verifica-se que o conceito de segurança mudou em três grandes dimensões (COMMISSION ON HUMAN SECURITY 2003):

- A preocupação com a segurança territorial deu lugar a uma preocupação, ainda maior, com a segurança das pessoas;

- O desenvolvimento sustentável das sociedades humanas, e não o seu armamento, deve ser a forma de assegurar a segurança das pessoas;

- A segurança humana envolve não apenas os governos, mas uma ampla participação de diferentes actores (individuais e colectivos) a nível local, regional e internacional.

Verifica-se assim, que este novo conceito de segurança humana, tal como foi definido pelas Nações Unidas, em 1994, completa a segurança do Estado, contribui para o exercício dos direitos do homem e reforça o desenvolvimento humano. A segurança humana pretende proteger os cidadãos de um vasto conjunto de perigos para o indivíduo e para a colectividade e, para além disso, visa dar-lhes os meios de agir em nome próprio. Esta noção de segurança humana faz apelo à ideia de um mundo global e em rede, em que os desafios e ameaças que enfrenta são problemas globais, havendo uma necessidade de reforçar as políticas institucionais que ligam os indivíduos ao Estado e o Estado ao conjunto dos outros Estados.

Para além disso, este conceito reconhece as ligações entre ambiente e sociedade e a complexidade dessas relações. Esta perspectiva 
mais ampla, também evita o erro da definição de relações causais directas entre mudança ambiental ou degradação ou escassez de recursos e de insegurança ou de conflito.

\section{Mudança global em África}

Embora a mudança ambiental não seja uma novidade em África, o ritmo das mudanças acelerou nas últimas décadas (UNEP 2008). Em África, o crescimento populacional, a rápida urbanização, as alterações climáticas, as escolhas insustentáveis de desenvolvimento e a governança frágil persistem como desafios críticos para atingir, a nível regional, as dimensões ambientais e sociais das metas de desenvolvimento (UNEP 2012).

África é um dos continentes mais vulneráveis à Mudança Global, facto que é agravado pela interacção de múltiplas pressões ambientais com baixos níveis de capacidade de adaptação. O continente africano apresenta um grande crescimento populacional, facto que induz grandes pressões sobre o ambiente, nomeadamente devido à necessidade de produção de bens alimentares, abastecimento de água e produção de energia. As mudanças de uso do solo estão a ocorrer de forma muito rápida, com expansão da superfície agrícola e declínio da superfície florestal.

Neste quadro geral, a vulnerabilidade aos impactos da mudança global não será idêntica em todos os países do continente. Contudo, é possível indicar algumas tendências gerais que constituem verdadeiros desafios ao desenvolvimento nesta região e que contribuem fortemente para agravar a vulnerabilidade e a fraca capacidade de adaptação do continente africano à mudança ambiental global (OTTER, OLAGO e NIANG 2007):

- Pobreza crescente e generalizada e recursos financeiros limitados;

- Grande dependência dos rendimentos familiares relativamente a actividades que assentam na utilização de recursos naturais como os solos, a água e a floresta;

- Crescimento da população muito rápido, estimando-se um crescimento de $127 \%$ em 2050;

- Forte dependência das economias de muitos países relativamente a um sector agrícola de baixa produtividade;

- Fracos níveis de bem-estar humano, estando a generalidade dos 
países africanos nos níveis mais baixos do Índice de Desenvolvimento Humano das Nações Unidas;

- Grande prevalência de doenças sensíveis aos elementos de clima (malária, meningite, cólera, febre do Vale do Rifte);

- Baixos níveis de qualificação e de desenvolvimento tecnológico;

- Sistemas de governança frágeis e complexidade das instituições;

- Persistência de conflitos regionais armados violentos.

Todos estes factores afectam a capacidade de África para lidar com a mudança ambiental global. A identificação de estratégias destinadas a mitigar ${ }^{3}$ os efeitos da mudança global necessita de envolver de forma integrada: o desenvolvimento socioeconómico e os sistemas de governança, as estratégias de adaptação ${ }^{4}$ e o desenvolvimento sustentável dos recursos naturais.

A necessidade de implementar estratégias de adaptação, de modo a que o impacto da mudança global possa ser minimizado, é particularmente acutilante em África. Isso deve-se principalmente ao facto de, devido aos elevados níveis de pobreza, as prioridades nacionais de muitos países africanos estarem centradas em torno da redução da pobreza e do desenvolvimento económico e não tanto em torno das alterações climáticas ou de outras mudanças ambientais. Para além disso, as competências técnicas insuficientes, a baixa capacidade de investigação e de inovação, a falta de instituições capazes de lidar com a adaptação e governança, conduziram muitas comunidades a implementar medidas tradicionais de adaptação, de baixo custo, para lidar com a mudança ambiental. No entanto, estas não são suficientes para enfrentar os efeitos da mudança global. São necessários esforços para melhorar as tecnologias tradicionais, apoiando a oportunidade para a introdução de tecnologias inovadoras e mais eficientes.

Em África, a definição de estratégias de mitigação e de adaptação à mudança global enfrenta ainda uma dificuldade acrescida devido à

3 De acordo com o IPCC (2001), as estratégias de mitigação referem-se a intervenções humanas destinadas a reduzir as fontes ou a desenvolver os sumidouros de gases com efeito de estufa. Deste modo, ao nível da mudança global, estas estratégias têm por alvo as causas das mudanças ambientais.

4 De acordo com o IPCC (2001), as estratégias de adaptação referem-se aos ajustamentos nos sistemas naturais ou humanos, em resposta a estímulos climáticos, ocorridos ou previstos, ou aos seus efeitos, e que atenuam danos ou exploram oportunidades benéficas. Assim, em termos de mudança global, estas estratégias têm por alvo os impactos das mudanças ambientais. 
escassa disponibilidade de informação e de dados fiáveis, que permitam a adequação das estratégias às condições (ambientais e socioeconómicas) locais.

\subsection{Uma população que se urbaniza}

Em 2013, a população de África atingiu cerca de 1.111 milhões de habitantes, tendo crescido $2,51 \%$ por ano, entre 1950 e 2013 , quase um ponto percentual a mais do que a taxa global de $1,65 \%$ por ano (UNDESA 2013). Para além disto, as Nações Unidas estimam que a população do continente africano terá a taxa de crescimento mais rápida do mundo, entre 2000 e 2050, o dobro da taxa de qualquer outra região durante esse período (UNDESA 2013).

A África tem sido o grande contribuinte para o rápido crescimento da população urbana mundial verificado nas últimas décadas. Contudo, continuará a ser o Continente menos urbanizado. Entre 1950 e 2000 a sua população urbana multiplicou-se por 9, passando de 32 para 279 milhões de pessoas; em 2030, cerca de metade da sua população viverá já em centros urbanos: 53,5\% contra valores acima dos $70 \%$ nas restantes regiões do mundo que iniciaram décadas antes o seu processo de urbanização (UN-HABITAT 2010; UNDESA, 2012).

O continente africano tem de se preparar para um aumento da população total de cerca de 60\%, entre 2010 e 2050, com a população urbana a triplicar para 1,23 mil milhões durante este período (UN--HABITAT 2010). Em 2010, existiam em África 47 cidades com mais de um milhão de habitantes, cuja população combinada era no total de cerca de 126,4 milhões de pessoas. A população total destas 47 cidades aumentou 17,3 milhões, entre 2005 e 2010. Uma vez que, no mesmo período, a população urbana total aumentou 63,8 milhões, torna-se claro que as maiores cidades apenas estão a absorver uma parcela relativamente pequena (27\%) das pessoas que se deslocam em direcção às áreas urbanas para aí passarem a residir. A maior parte $(73 \%)$ deslocou-se para as cidades com populações inferiores a um milhão de habitantes (UN-HABITAT 2010).

Uma vez que as cidades são o habitat futuro para a maioria dos africanos, agora é o momento para o investimento nas infra-estruturas básicas, nos serviços sociais (saúde e educação), na habitação a preços acessíveis, no processo de dinamização das economias urbanas e de criação de emprego (LourEnço 2013). Este investimento 
deve ser acompanhado pela melhoria da capacidade de gestão das áreas urbanas, nomeadamente Os governos africanos devem buscar outras melhorias nas cidades com menos de um milhão de habitantes.

\section{2. Água: a competição por um recurso}

A disponibilidade e o acesso à água doce é uma condicionante importante dos padrões de crescimento económico e de desenvolvimento de qualquer sociedade. Esta situação é particularmente importante em África, onde a maioria das pessoas vive em áreas rurais e está fortemente dependente da agricultura para a sua subsistência.

O continente africano é provido de recursos hídricos em abundância. No entanto, fenómenos naturais, tais como os padrões espaciais de precipitação, a variabilidade natural no regime das chuvas e as alterações climáticas, juntamente com factores humanos, tais como o crescimento da população, a competição pelo recurso, e a sua degradação por poluição, ameaçam cada vez mais a sustentabilidade dos recursos hídricos neste continente.

Os recursos hídricos renováveis para o conjunto de África atingem cerca de $3.930 \mathrm{~km} 3$, ou seja menos de $9 \%$ dos recursos hídricos renováveis globais (FRENKEN 2005). O consumo de água per capita, em África, é de cerca de 31m3 por ano, sendo comparativamente menor do que em outras regiões, como, por exemplo, na América do Norte onde cada pessoa consome, em média 221m3 por ano (UNESCAP 2007). A agricultura é, de longe, a responsável pela maior parte da captação e do consumo de água em África. A irrigação de terras agrícolas regista-se, fundamentalmente, nas regiões áridas e semiáridas do norte e do sul do continente e ao longo do Sahel. Nestas áreas, a maior parte dos recursos hídricos superficiais e subterrâneos são fortemente explorados.

A falta de água restringe frequentemente as actividades humanas, nomeadamente a agricultura, enquanto a poluição da água diminui a sua disponibilidade sendo uma fonte de doenças. As alterações climáticas irão agravar esta situação. Estima-se que mais de 300 milhões de pessoas em África enfrentem condições de escassez de água. ${ }^{5}$

5 A situação de escassez de água verifica-se quando estão disponíveis menos de $1000 m^{3}$ de água potável por pessoa por ano. Diz-se que há uma situação de stress hídrico quando estão disponíveis menos de $1700 \mathrm{~m}^{3}$ de água potável por pessoa por ano (UNEP 2002). 
Em 2050, estima-se que as zonas afectadas por escassez de água na África subsahariana aumentem em 29\% (UNEP 1999). A captação e o consumo de água têm aumentado nas últimas décadas. Contudo, os recursos hídricos disponíveis do continente têm vindo a diminuir, principalmente como resultado de situações de seca persistente e de mudanças nos padrões de uso do solo (UNEP 2008).

A maioria da população da África subsahariana encontra-se exposta a uma situação de escassez económica de água. Esta escassez resulta da população não possuir os meios monetários necessários para utilizar fontes adequadas de água. Motivos políticos e conflitos étnicos têm contribuído para esta distribuição desigual de recursos. A escassez económica de água pode ser ultrapassada de forma relativamente rápida e eficaz através da construção de infra-estruturas simples para recolher a água das chuvas e de barragens, mas isso requer investimentos económicos que muitas dessas áreas não possuem devido a uma ausência de desenvolvimento industrial e pobreza generalizada (MOLDEN 2007).

\section{5•3. A desflorestação}

De acordo com o mais recente Global Forest Resources Assessment (FRA 2010), estima-se que a área florestal, em África, esteja perto de 675 milhões de hectares, o que representa cerca de $17 \%$ da área florestal mundial e 23 \% da área total do continente (FAO 2011).

A taxa de desflorestação em África é maior do que em qualquer outro continente, embora esteja a diminuir desde a década de 1990 (Kelatwang e Garzuglia 2006). Houve uma redução na taxa líquida de perda de florestas na região, que passou de 4 milhões de hectares por ano (o,56\%/ano), na década 1990-2000, para 3,4 milhões de hectares por ano (o,49\%/ano) durante o período 2000-2010 (FAO 2011). Produção de madeira, conversão de terras para a agricultura e urbanização, incêndios florestais, corte para lenha e carvão vegetal, e distúrbios civis são as principais causas da desflorestação em África, impulsionadas na maior parte dos casos pelo crescimento da população.

A conversão de florestas em terras agrícolas é necessária para a produção de alimentos, mas esta desflorestação afecta negativamente os ecossistemas locais, havendo perda de habitats. Para além disso, a desflorestação é, em África, um dos principais motivos para a 
degradação do solo, especialmente quando seguido por intensificação da agricultura e pelo aumento das áreas de pastagens para a produção pecuária.

\subsection{A degradação dos solos: uma ameaça à segurança alimentar}

Estima-se que, em África, a degradação dos solos, enquanto processo de redução da capacidade dos solos para produzirem alimentos ou materiais, afecte $65 \%$ dos solos agrícolas, $31 \%$ das áreas de pastagem e $19 \%$ da superfície florestal (FAO 2005). Mais de um quarto das regiões áridas e semiáridas de África apresenta uma degradação significativa devida à erosão do solo, perda de nutrientes, poluição ou salinização (WhiтE et al., 2000). Em geral, a única opção para os agricultores mais pobres é a de cultivarem ou criarem gado em terras marginais, facto que pode levar a um ciclo de aumento da erosão e degradação do solo, conduzindo, eventualmente, à desertificação.

A fertilidade dos solos do continente africano está a diminuir a uma taxa que constitui uma ameaça para as tentativas de erradicação da fome. É nesta degradação dos solos que se pode encontrar uma das explicações para a estagnação, nas últimas quatro décadas, da produtividade agrícola neste continente. De facto, as práticas agrícolas desajustadas prejudicaram, entre 1980 e 2004, a fertilidade dos solos em África (HENAO e BAANANTE 2006).

No continente africano, a agricultura representa, em média, cerca de $65 \%$ da força de trabalho e cerca de $32 \%$ do PIB, facto que reflecte uma produtividade relativamente baixa (WORLD BANK 2011). No entanto, a agricultura está altamente concentrada, com o Egipto e Nigéria a serem responsáveis por um terço da produção agrícola total (JAYARAM et al., 2010).

Isto constitui um grande desafio para a segurança alimentar em África. Para além disso, na África Subsahariana, os sistemas de produção agrícola dependem fortemente da irrigação pela chuva, pelo que a produção alimentar é extremamente vulnerável a condições meteorológicas adversas.

O continente africano continua a apresentar situações de segurança alimentar e nutricional marcadas por vários episódios críticos de diminuição dos meios de subsistência (UN MILLENNIUM PROJECT 2005; LOBELL 2008). 
Para satisfazer as crescentes necessidades de consumo, associadas ao crescimento populacional, a maioria dos países africanos vai necessitar de aumentar a produtividade a agrícola e/ou expandir as áreas cultivadas (FADER et al., 2013), contribuindo, assim, para a redução da situação de insegurança alimentar e nutricional, cujas causas assentam fortemente na pobreza e na escassez de alimentos.

\section{Governança para a sustentabilidade}

Governança refere-se ao sistema global de instituições públicas e privadas, princípios, normas, regulamentos, procedimentos decisórios e organizações que intervêm numa determinada área da política mundial (BIERMANn et al., 2009). Permite-nos compreender a forma como os governos operam; quem está envolvido nos processos de tomada de decisão; de que modo o Estado e os actores sociais interagem; e a equidade da distribuição dos custos e benefícios. A noção de governança em múltiplos níveis (multi-level governance) dá expressão à ideia de que devem ser consideradas as diferentes estruturas de autoridade que interagem em contexto de mudança ambiental, que é ao mesmo tempo um problema global, regional, nacional e local e que exige respostas políticas globais e locais. Além disso, como o caminho para a sustentabilidade aumenta a complexidade da nossa sociedade global e pós-industrial, torna-se necessário discutir as estruturas básicas de governança, a fim de gerir os conflituantes e dinâmicos sistemas económicos, sociais e ambientais.

A governança do Sistema Terra não está, deste modo, confinada aos Estados e aos governos. Caracteriza-se pela participação de inúmeros actores públicos e privados em todos os níveis de decisão, desde redes de especialistas, ambientalistas e empresas multinacionais até organismos governamentais. A governança do Sistema Terra pode, assim, ser vista como a soma dos sistemas de regras formais e informais, envolvendo um número crescente de actores apostados em reforçar a actual arquitectura de instituições e redes a nível local e global (BIERMANn et al., 2009).

Assim, um sistema de governança global não significa nem a criação de um governo mundial, nem a criação de novas instituições poderosas. Trata-se de reforçar a coerência, eficácia e legitimidade das instituições já existentes; de identificar e preencher as lacunas na arquitectura institucional multilateral e regulamentar; e de conceber, 
apenas quando imprescindível, novas instituições (CoOLSAET e ARNOULD 2004).

De acordo com Giddens, «[...] in a global era, the state operates within the context of what political scientists call multilayered governance, stretching upwards into the international arena and downwards to regions, cities and localities [...]» (GIDDENs 2009: 5). Este modelo de governança requer a integração de uma dimensão global, assegurando, no entanto, a preservação das identidades locais e regionais e a aceitação das respostas por parte dos cidadãos. Portanto, a governança para a sustentabilidade não está confinada aos Estados e governos enquanto actores únicos. Tem de se estruturar em múltiplos níveis e deve articular a participação das numerosas redes de actores sociais (públicos e privados; individuais ou colectivos) em todos os níveis de tomada de decisão. Os Estados terão que trabalhar com uma variedade de outros órgãos e entidades, bem como com outros países e organizações internacionais para que possam ser eficazes.

No quadro da gestão dos recursos naturais, os sistemas sociais são importantes agentes de mudança: não apenas produzem e estão expostos a mudanças na disponibilidade dos recursos, como desenvolvem várias acções para mitigar ou se adaptar a estas mudanças (GWSP 2005). A boa governança dos recursos naturais obriga, assim, à reforma dos processos de tomada de decisão, aumentando as oportunidades de participação pública na sua gestão. Para isso é necessário aumentar o debate público e a capacidade de resolução de problemas.

A participação na gestão do ambiente, do território e dos recursos naturais é justificada pelos benefícios para as comunidades locais, resultantes da proximidade entre os actores locais e os recursos, facto que poderá garantir uma utilização mais adequada dos recursos; através de processos mais flexíveis que possam garantir uma melhor adaptação aos contextos de incerteza e de mudança (BROWN 1999). $\mathrm{Na}$ verdade, o envolvimento dos actores locais nos processos de tomada de decisão é um processo vantajoso, pois promove (LouRENÇo et al., 2004; Gonsalves et al., 2005): políticas inovadoras e acções de planeamento estratégico mais bem informadas; resolução de conflitos; melhor aceitação por parte dos actores interessados; continuidade e coerência nas políticas; coordenação e integração das diferentes acções. Deste modo, a participação de actores locais nos processos de tomada de decisão implica mobilizar as suas próprias capacidades transformando-os, portanto, em agentes activos em vez de sujeitos 
passivos (JiCA 1995; Machado et al., 2002). Contudo, este tipo de participação na tomada de decisões ambientais ainda enfrenta dificuldades para ser implementada, existindo, por vezes, fortes constrangimentos administrativos à participação do público na definição das opções de política ambiental (Gonsalves et al., 2005).

Assim, à medida que as fronteiras entre público e privado se vão modificando, um dos passos mais importantes para a gestão dos recursos naturais passa por envolver a comunidade científica, os decisores políticos e os representantes da sociedade civil na discussão de experiências e de novas estratégias de gestão sustentável de recursos, no sentido de satisfazer as necessidades da população e das actividades socioeconómicas, assegurando a melhoria das condições de vida, a diversificação das formas de rendimento e a conservação ambiental (CEC 2001; MACHADO et al., 2002).

As acções e políticas de mitigação, que têm por alvo as causas das mudanças ambientais, e de adaptação, que têm por alvo as consequências das mudanças ambientais, são complementares e exigem novos sistemas de governança, nos quais os Estados devem desempenhar um papel de liderança na definição e execução das políticas: A mitigação é, antes de mais, da competência dos governos nacionais, no âmbito das negociações internacionais; A adaptação insere-se na esfera dos gestores de recursos locais, das famílias e das empresas, no contexto de uma economia e sociedade regional. Tal como os esforços de redução das alterações ambientais, a adaptação à Mudança Global tem de ser antecipativa e preventiva, mais do que reactiva. As medidas de adaptação implicam: pensar no futuro de forma sistemática, antevendo as consequências das alterações ambientais; identificar detalhadamente as vulnerabilidades existentes a nível local, regional e nacional.

As políticas de mitigação e de adaptação têm, assim, de convergir, porque se justapõem, com outras políticas públicas: segurança ener308 gética, inovação tecnológica, mobilidade e transportes, ordenamento do território, etc., pelo que a Mudança Global tem de estar no cerne da agenda política.

Deste modo, a governança para a sustentabilidade debate-se com alguns problemas que a tornam um desafio particularmente difícil: a incerteza persistente quanto às causas das alterações ambientais globais, aos seus impactos, à interligação das várias causas e das opções de resposta possíveis, e aos efeitos destas últimas; as dependências intergeracionais que suscitam novos e excepcionais desafios em 
termos de governação; a amplitude extraordinária dos danos possíveis, para a qual os sistemas de governança actuais poderão não estar devidamente preparados.

\section{Da investigação em Mudança Global à investi- gação para a Sustentabilidade Global}

Desde o início da década de 1980, quatro programas internacionais, financiados pelo International Council for Science (ICSU), foram responsáveis pelo desenvolvimento da investigação e produção de conhecimento científico das dinâmicas do Sistema Terra. O International Geosphere-Biosphere Programme (IGBP) juntamente com o International Human Dimensions Programme on Global Environmental Change (IHDP), o World Climate Research Programme (WCRP), e o International Programme of Biodiversity Science (DIVERSITAS), constituíram a Earth System Science Partnership (ESSP) com o objectivo de proceder ao estudo interdisciplinar e integrado do Sistema Terra, das suas mudanças ambientais, sociais, económicas, culturais e institucionais, e das implicações dessas mudanças na sustentabilidade global e regional. O Estudo do Sistema Terra e o Desenvolvimento Sustentável obrigam a uma abordagem sistémica. Deste modo, a Earth System Science Partnership aborda a complexidade do Sistema Terra tentando individualizar as suas componentes, mas procurando fornecer o conhecimento científico que permita reunir as peças do puzzle. Os objectivos da investigação promovida por esta parceria eram: Analisar as interacções dos processos físicos, químicos e biológicos que definem as dinâmicas do Sistema Terra; Analisar as mudanças que afectam estas dinâmicas; Analisar o papel das actividades humanas nessas mudanças.

O Future Earth - Research for global sustainability é uma nova iniciativa internacional de investigação integrada para os próximos 10 anos. Este é um empreendimento internacional e transdisciplinar desenhado sob a forma de parceria. Tem por missão reorganizar as estruturas internacionais de investigação científica da Mudança Ambiental Global. Assenta no princípio da integração da compreensão do funcionamento do Sistema Terra de modo a encontrar soluções para uma transição para a sustentabilidade global.

Deste modo, pretende responder aos seguintes desafios: De que forma e porquê está o ambiente global a mudar? No futuro quais são 
as mudanças mais prováveis e quais são as implicações para o bemestar humano e para as outras espécies? Que opções devem ser escolhidas para reduzir os riscos e as vulnerabilidades e aumentar a resiliência? Como é que este conhecimento pode apoiar a tomada de decisões e as estratégias de desenvolvimento sustentável?

Esta iniciativa internacional estrutura-se em torno de três grandes temas de investigação:

1. Planeta Dinâmico: Observar, explicar, compreender, projectar as tendências, forças e processos de mudança ambiental e social do Sistema Terra; antecipando limiares e riscos globais.

2. Desenvolvimento Global: Fornecer o conhecimento para a gestão sustentável, segura e justa de alimentos, água, biodiversidade, saúde, energia, materiais e outras funções e serviços dos ecossistemas.

3. Transformação para a sustentabilidade: Compreender os processos de transformação e as opções, avaliando a forma como estes se relacionam com os valores humanos, tecnologias emergentes e os caminhos de desenvolvimento económico, e avaliar estratégias para governar e gerir o ambiente global em todos os sectores e escalas.

\section{Considerações finais}

Em quase todos os domínios da investigação da Mudança Ambiental Global, o papel dos seres humanos é um factor-chave enquanto força motriz, elemento exposto aos impactos, ou agente de mitigação e de adaptação à mudança.

As interacções do sistema integrado ambiente/sociedade reflectem-se nas formas como os territórios estão organizados, e caracterizam-se pela grande incerteza e complexidade, tornando difícil a tarefa de gerir as mudanças. A compreensão e análise dos problemas ambientais obriga a:

- Implementação de abordagens integradas e interactivas, que permitam a compreensão das interacções dos sistemas sociais e naturais;

- Assumir que o ambiente, apesar de ser uma dimensão crucial para o desenvolvimento sustentável das sociedades, tem de ser considerado num contexto de paridade com as dimensões social e económica da sustentabilidade. 
Em África, a promoção da sustentabilidade e a procura de melhor qualidade de vida para as populações enfrenta desafios de particular importância, nomeadamente os que estão relacionados com o acesso a água potável, ar limpo e alimentos; a adaptação dos sistemas de governança para promoção da sustentabilidade; a gestão de áreas urbanas; a redução da pobreza e a criação de rendimento. A questão da segurança e a criminalidade, particularmente nas áreas urbanas.

O estudo da Mudança Ambiental Global tem de envolver, desde o seu início, as ciências sociais, humanas, naturais e técnicas na criação de espaços de interdisciplinaridade, os seus termos de referência e as formas de articulação. Além disso, várias importantes disciplinas das ciências sociais como Direito, Arquitectura, História, Literatura, Comunicação, Economia, Gestão, Sociologia, Geografia e Psicologia são fundamentais para compreender as dinâmicas do Sistema Terra, as motivações humanas e para orientar os processos de tomada de decisão.

Esta perspectiva de integração tem de ser realizada associando diferentes abordagens científicas e níveis de análise. No entanto, a integração multidisciplinar não pode ser encarada como sinónimo de sobreposição ou de junção de diferentes abordagens empíricas. Ela pretende atingir uma lógica de articulação entre os diferentes domínios científicos e os diferentes níveis de análise espacial e temporal.

A análise temporal é um dos elementos fundamentais do desenho metodológico dos estudos sobre a Mudança Global e o Desenvolvimento Sustentável. Assim, se o objectivo deste tipo de investigação consiste na compreensão dos processos de mudança ambiental, é necessário atender, para além dos diferentes ritmos e ciclos dos diversos fenómenos, a vários momentos históricos. A análise deve considerar o diferente quadro biofísico e social que preside a cada momento. A forma de articulação de todo este conjunto de dados com diferentes origens é um dos grandes desafios desta investigação.

Neste momento, tanto a comunidade científica como os decisores políticos percepcionam a convergência entre a viabilidade económica e a protecção do ambiente como um passo importante para a sustentabilidade global. No entanto, a concretização desta percepção e a sua tradução em estratégias de investigação coerentes não é fácil. A comunidade científica tem ainda de produzir uma estrutura e um conjunto de metodologias robustas, dentro das quais essas estratégias possam ser desenvolvidas. A investigação dominante adoptou abordagens apenas relevantes para as disciplinas individuais, e a 
diferença de metodologias entre as várias disciplinas tende a impedir a integração eficaz de diferentes abordagens.

Na Figura apresenta-se uma metodologia construída durante o projecto ALENCOAST - Land Use Changes. Methodological Approach to Understand the Interactions Nature/Society in Coastal Areas (LouRENÇO et al., 1999), realizado para o Joint Research Centre da União Europeia, que permite desenvolver uma análise multidimensional das dinâmicas do território. A partir do nível regional (nacional ou global), onde é possível identificar as principais mudanças socioeconómicas e biofísicas, atinge-se o nível local para compreender a complexidade das interacções presentes no sistema socio-ecológico. Esta metodologia constitui uma ferramenta importante para a construção de instrumentos de apoio à tomada de decisão. A aplicação desta metodologia em diferentes contextos geográficos e socioeconómicos pode ser apreciada em estudos realizados no Brasil, Índia e Bacia do Mediterrâneo (Lourenço et al., 1999; NoronhA, Lourenço et al., 2003; LourençO e Jorge 2003; Lourenço et al., 2006; Lourenço et al., 2004; MACHADI, REISDORFF e DuRIAVIg 2004).

Figura 1. Metodologia para análise integrada e interdisciplinar de dinâmicas do território

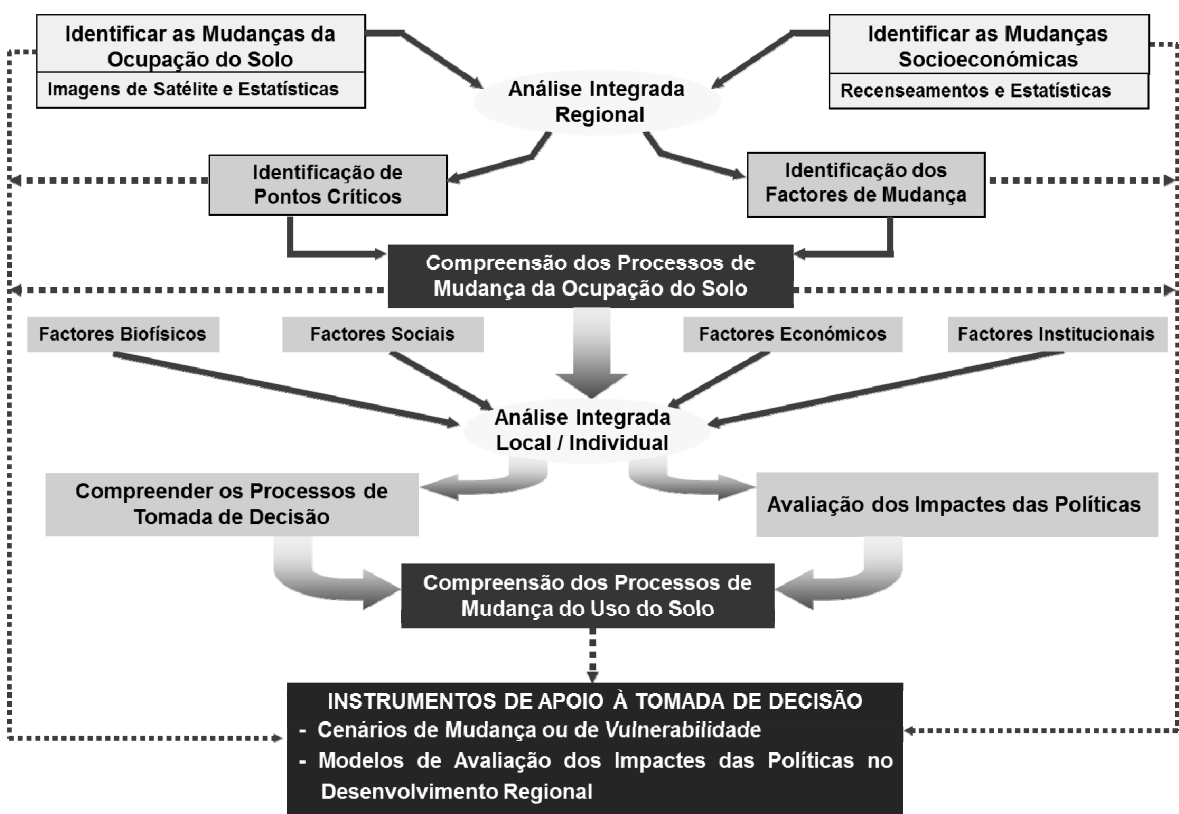

Fonte: Lourenço et al. (1999). 
A maioria dos estudos tende a concentrar-se sobre os efeitos e os impactos da acção humana sobre o ambiente, dedicando pouca atenção às consequências dessas alterações nas actividades humanas. Estudos sobre o papel que a humanidade joga na mudança global são frequentemente realizados dentro do conceito de uma análise da dimensão humana. Perdem, assim, a perspectiva sistémica que considera a sociedade como um subsistema em interacção com o subsistema natural dentro do quadro integrado que é o Sistema Terra.

O uso desta perspectiva sistémica permite que a complexidade das interacções definidas pelos sistemas sociais e naturais, possam ser incorporadas na análise e obriga ao desenvolvimento de uma visão diferente sobre a relação desses dois sistemas. Esta visão mostra que eles interagem através da lógica de reflexividade. Em outras palavras, os sistemas sociais são alterados ao mesmo tempo em que modificam o sistema natural, ou seja, o impacto da actividade humana sobre o ambiente e as consequências da degradação deste último sobre a actividade humana não podem ser considerados separadamente, uma vez que estão relacionados em tempo real.

A base científica desta perspectiva é a crença de que a integração das ciências naturais e das ciências sociais no estudo da Mudança Ambiental Global representa um meio conceptualmente correcto de abordar a questão unificadora das sustentabilidades social, económica e ambiental.

Este quadro é particularmente significativo no contexto de África, onde a Mudança Global apresenta indicadores mais desfavoráveis, onde as vulnerabilidades são muito significativas e onde as tendências de mudança são rápidas e intensas. Neste contexto, as estratégias de sustentabilidade têm forçosamente de integrar as perspectivas e conhecimentos das ciências sociais na análise da mudança ambiental global e na definição de estratégias e políticas de desenvolvimento.

\section{Referências Bibliográficas}

Adger W. N., Brown K. e Hulme M.

2005, «Redefining global environmental change», Global Environmental Change, n. ${ }^{\circ} 15$, pp. 1-4.

Becker E., JAhn T., Stiess I., Wehling P.

1997, Sustainability: A cross-disciplinary concept for social transformations. Paris, unESCO/MOST [«Policy papers»; n..$^{\circ} 6$ ]. 
Biermann F., Pattberg P., Asselt H. van, Zelli F.

2009, «The fragmentation of Global Governance Architectures: A framework for analysis», Global Environmental Politics, Vol. 9, n. ${ }^{\circ}$, pp. 14-40.

BROWN D.

1999, Principles and practice of forest co-management: Evidence from West-Central Africa. Londres, ODI e Bruxelas, European Commission [«European Union Tropical Forestry, Paper 2»].

CEC - COMMISSION OF THE EUROPEAN COMMUNITIES

2001, European Governance: A White Paper. Bruxelas, Commission of the European Communities. Disponível em <europa.eu/ rapid/press-release_DOC-01-10_en.htm>

COMMISSION ON HUMAN SECURITY

2003, Human Security Now. New York, United Nations.

CoOlsaet R. e Arnould V.

2004, Global Governance: The Next Frontier. Bruxelas, Royal Institute for International Relations [«Egmont Paper»; 2].

Crutzen P. J. e Stoermer E. F.

2000, «The Anthropocene», Global Change Newsletter, n. ${ }^{\circ} 41$, pp. 17-18.

Fader M., Gerten D., Krause M., Lucht W. e Cramer W.

2013, "Spatial decoupling of agricultural production and consumption: quantifying dependences of countries on food imports due to domestic land and water constraints», Environmental Research Letters, vol. 8, n. ${ }^{\circ}$ 1, March. <http://dx.doi.org/10.1088/17489326/8/1/014046>

FAO - FOOD AND AGRICULTURE ORGANISATION OF THE UNITED NATIONS

2005, State of the World's Forests 2005. Roma, Food and Agriculture Organization of the United Nations.

FAO - FOOD AND AGRICULTURE ORGANISATION OF THE UNITED NATIONS

2011, State of the World's Forests 2011. Roma, Food and Agriculture Organization of the United Nations.

FRENKEN K.

2005. Irrigation in Africa in figures: AQUASTAT Survey 2005. Roma, Food and Agriculture Organization of the United Nations [«FAO Water Reports»; 29].

GidDENS A.

2009. Politics of climate change. Cambridge, Polity Press.

Gonsalves J., Becker T., Braun A., Campilan D., Chavez H. de, FaBer E., Kapiriri M., Rivaca-CAminade J. e Vernooy R. (eds.)

2005, Participatory research and development for sustainable 
agriculture and natural resource management: $A$ sourcebook, 3 volumes. Los Baños, Filipinas, International Potato Center-Users' Perspectives With Agricultural Research and Development; e Ottawa, Canada, International Development Research Centre.

Goudie A. S.

2000 ( $5 \cdot^{\mathrm{a}}$ edição), The Human Impact on the Natural Environment. Oxford, Blackwell Publishers.

GWSP - GLOBAL WATER SYSTEM PROJECT

2005, The Global Water System Project: Science framework and implementation activities. Bonn, Earth System Science Partnership.

Henao J. e BaAnANTE C.

2006, Agricultural production and soil nutrient mining in Africa: Implications for Resource Conservation and Policy Development. Muscle Shoals, International Center for Soil Fertility and Agricultural Development.

IGBP - THE INTERNATIONAL GEOSPHERE-BIOSPHERE PROGRAMME

2006, Science Plan and Implementation Strategy. Estocolmo, IGBP Secretariat [«IGBP Report»; n. ${ }^{0}$ 55]

JAYARAM K., Riese J. e SANGHVI S.

2010, Africa's path to growth. Agriculture: Abundant opportunities. New York, McKinsey Global Institute.

JICA - JAPAN INTERNATIONAL COOPERATION AGENCY

1995, Participatory development and good governance. Report of the Aid Study Committee. Tóquio, Japan International Cooperation Agency.

Johnston R. J., TAYlor P. J. e Watts M. (eds.)

2002 (2. ${ }^{\mathrm{a}}$ edição), Geographies of global change: Remapping the World. Oxford, Wiley-Blackwell.

Kelatwang S. e Garzuglia M.

2006, "Changes in forest area in Africa 1990-2005", International Forestry Review, n. ${ }^{\circ}$ 81, pp. 21-30.

Lobell D. B., Burke M. B., Tebaldi C., Mastrandrea M. D., Falcon W. P. e NAYLOR R. L.

2008, «Prioritizing climate change adaptation needs for food security», Science, n. ${ }^{\circ} 319$, pp. 607-610.

LOURENÇO N.

2013, «Globalização, metropolização e insegurança: América Latina e África» RDeS - Revista de Direito e Segurança (Lisboa), n. ${ }^{\circ}$ 1, pp. 87-116.

2005, «Equity, human security, and environment: key elements of sustainable development», in J. França Martins, L. Rodrigues 
e T. M. Fernandes (coords.), Cooperar para o desenvolvimento. Oeiras, Instituto Nacional de Administração, pp. 20-28.

2001, «Equity, human security, and environment: key elements of sustainable development», Coastin. A Coastal Policy Research Newsletter, n. ${ }^{\circ}$ 5, pp. 2-4.

Lourenço N., Jorge R., Machado C. R. e Rodrigues L.

1999, Land use change: Methodological approach to understand the interactions Nature/Society in coastal areas. ISPRA, JRC/ARISSAI, European Commission.

Lourenço N., Machado C. R. e Jacinto J. J.

2004, Typology of the main socio-economic pressures, factors and agents of change in Cachoeira catchment and Central Costa Rica. Barcarena, Universidade Atlântica.

Lourenço N., Machado C. R. e Rodrigues L.

2006, Social issues in water management in the Mediterranean Countries. Report for the NOSTRUM Project. Barcarena, Universidade Atlântica.

Lourenço N., Rodrigues L. e Machado C. R.

2004, Report on social issues in Water Management in The Mediterranean Countries. Disciplinary Report of the Network on Governance, Science and Technology for Sustainable Water Resource Management in the Mediterranean - The role of Dss tools NOSTRUM-DSS, 76p.

LOURENÇO N. e JoRge R.

2003, Tourism: spatial dimension and driving force, in L. Noronha et allii. (eds.), Coastal tourism, environment and sustainable local development. New Delhi, TERI - The Energy Research Institute, pp. 31-60.

Lourenço N., Correia T. P., Jorge R. e Machado C. R.

1999, «Understanding the interactions nature/society for land use management in rural areas. Monitoring and managing land use methodology», in L'ubomír Falt'an (ed.), Europe: Expectations and reality. The challenge for the Social Sciences. Bratislava, Slovak Academy of Sciences.

Machado C. R., Lourenço N., Jorge M. R. e Rodrigues L. 2002, «Sustainability: Importance of social networks in the decision-making processes», in Proceedings of the conference policies and tools for sustainable water management in the $E U$.

Machado C. R., Reisdorff C. e Duriavig M. 2004, The challenge of sustainable ecosystem development in Cachoeira catchment (South Bahia, Brazil). Barcarena, Universidade Atlântica, 81p. 
MCKINSEY \& COMPANY

2013, Infrastructure Productivity: how to save \$1 trillion a year. New York, McKinsey Global Institute.

Molden D.

2007, Water for food, water for life. Comprehensive assessment of water management in agriculture. Londres, Earthscan Publications.

Noronha L., Lourenço N., Ferreira J. P. L.; Lleopart A., Feoli E., SaWkar K. e Chachadi A. (eds.)

2003, Coastal tourism, environment and sustainable local development. New Delhi, TERI - The Energy Research Institute.

ODum E. P.

1953, Fundamentals of ecology. Philadelphia, W. B. Saunders Company.

OldField F. e StefFen W.

2004, «The earth system», in W. Steffen, A. Sanderson, P. Tyson, J. Jäger, P. Matson, B. Moore III, F. Oldfield, K. Richardson, H.-J. Schellnhuber, B. L. Turner II e R. Wasson (eds.), Global change and the earth system: A planet under pressure. Berlin, Heidelberg, New York, Springer-Verlag [«IGBP Global Change Series»].

Otter L., Olago D. O. e Niang I. (eds.)

2007, Global change processes and impacts in Africa: A synthesis. Nairobi, East African Publishers Ltd.

PAELKE R.

1999, «Towards defining, measuring and achieving sustainability: tools and strategies for environmental valuation» in Egon Becker e Thomas Jahn (eds.), Sustainability and Social Sciences. A crossdisciplinary approach to integrating environmental considerations into theoretical reorientation. Londres, Zed Books, pp. 243263.

Rockström J., Steffen W., Noone K., Persson Å., Chapin ili F. S., Lambin E., Lenton T. M., Scheffer M.; Folke C., Schellnhuber H., Nykvist B., De Wit C. A., Hughes T., Leeuw S. van der, Rodhe H., Sörlin S., Snyder P. K., Constanza R., Svedin U., Falkenmark M., Karlberg L., Corell R. W., Fabry V. J., Hansen J., Walker B., Liverman D., Richardson K., Crutzen P. e Foley J.

2009, «Planetary boundaries: exploring the safe operating space for humanity», Ecology and Society, vol. 14 (2), n. ${ }^{\circ}$ 32, pp. 1-33.

Steffen W., Sanderson A., Tyson P., Jäger J., Matson P., Moore iII B., Olfield F., Richardson K., Schellnhuber H.-J., Turner iI B. L., WASSON R. (eds.)

2004, Global change and the earth system: A planet under pres- 
sure, Berlin, Heidelberg e New York, Springer-Verlag [«IGBP Global Change Series»].

\section{SYVITSKI J.}

2012, "Anthropocene: an epoch of our making», Global Change Newsletter, n. ${ }^{\circ}$ 78, pp. 12-15.

TANSLEy A. G.

1935, «The use and abuse of vegetational concepts and terms», Ecology, n. ${ }^{\circ}$ 16, pp. 284-307.

UN MILLENNIUM PROJECT

2005, Halving hunger: It can be done. Task force on hunger. Londres, Earthscan Publications.

UNDESA

2012, World urbanization prospects: The 2011 Revision. New York, United Nations, Department of Economic and Social Affairs, Population Division.

2013, World Population Prospects: The 2012 Revision. New York, United Nations, Department of Economic and Social Affairs, Population Division.

UNEP

1999, Global Environment Outlook-20oo. Nairobi, United Nations Environment Programme.

2002, Africa Environment Outlook. Past, present and future perspectives. Nairobi, United Nations Environment Programme.

2008, Africa. Atlas of our changing environment. Nairobi, United Nations Environment Programme

2012, GEO5 - Global Environment Outlook. Environment for the future we want. Nairobi, United Nations Environnent Programme.

UNESCAP

2007, Statistical Yearbook for Asia and the Pacific 2007. Bangkok, United Nations Economic and Social Commission for Asia and the Pacific.

\section{UNESCO}

318

2009. Water in a changing world. The United Nations World Water Development Report 3. Paris, United Nations Educational, Scientific and Cultural Organization

UN-HABITAT

2010, The State of African Cities 2010. Governance, Inequality and Urban Land Markets. Nairobi, United Nations Human Settlements Programme.

WAINWRIGHT J.

2009, «Earth-system science», in N. Castree, D. Demeritt, D. 
Liverman, e B. Rhoads (eds). A companion to environmental geography. Oxford, Wiley-Blackwell, pp. 145-167.

White R., MurRay S. e RorWEDER M.

2000, Pilot analysis of global ecosystems: Grassland ecosystems. Washington, World Resources Institute.

WORLD BANK

2011, Fact sheet: The World Bank and agriculture in Africa. Washington, World Bank.

Recepção do manuscrito: 17/11/2015

Conclusão da revisão: 04/04/2016

Aceite para publicação: 10/04/2016

Title: The Social Sciences and global environmental change. Challenges for Sustainable Development in Africa.

\begin{abstract}
Human activities are changing the Earth System, with significant impacts on the environment at local, regional and global levels. Climate change and biodiversity loss hinder the improvement of human welfare and poverty alleviation.

At global level it is essential to understand how the pressures on ecosystems constitute a risk to the functioning of the Earth System, in general, and society, in particular. In Africa, the promotion of sustainability and the demand for better quality of life for people is facing challenges of particular importance, especially those related to the access to safe drinking water, clean air and food, the adaptation of governance systems to promote sustainability, the management of urban areas, poverty alleviation and income generation.

In this lecture, it is proposed a new theoretical and analytical multidisciplinary framework for the study of some critical issues for the development and global sustainability: Food security, water security, energy security, health security and human security. This new conceptual framework must produce and integrate new knowledge in areas such as: governance and thresholds of change; sustainable use of natural capital and biodiversity conservation; lifestyles, ethics and values; economic and social implications of technological changes associated with the transition to economies with low carbon intensity.

Considering the scale and impacts of human activities, strategies for sustainability must necessarily integrate the perspectives and knowledge of the social sciences in the analysis of global environmental change and in the definition of strategies and development policies.
\end{abstract}

Palavras-chave: Earth system, global change, development, sustainability, integrated analysis, governance, Africa.

\title{
Nelson Lourenço
}

Doutor em Sociologia pela Universidade Nova de Lisboa (UNL), com agregação em Sociologia do Desenvolvimento e da Mudança Social pela mesma universidade, foi Professor Catedrático da Faculdade de Ciências Sociais e Humanas (FCSH-UNL) actualmente é Professor Catedrático Convidado da Faculdade de Direito da Universidade Nova de Lisboa. É Presidente do Grupo de Reflexão Estratégica sobre Segurança 
Interna (GRESI) e da direcção do Instituto de Direito e Segurança (FD-UNL).

Publicou, entre outros, os materiais seguintes: «Globalização e glocalização O difícil diálogo entre o global e o local», Mulemba - Revista Angolana de Ciências Sociais (Lisboa), vol. iv, n. ${ }^{\circ}$ 8, Novembro de 2014, pp. 17-31; «Globalização, metropolização e insegurança: América Latina e África», Revista de Direito e Segurança (Lisboa), vol. 1, n. ${ }^{\circ}$, 2013, pp. 87-116; «Modernidade, globalização e nacionalismos», $M u-$ lemba - Revista Angolana de Ciências Sociais (Luanda), vol. III, n. ${ }^{\circ}$ 6, Novembro de 2013, pp. 283-301; «Mudança global e geopolítica dos recursos naturais», Mulemba - Revista Angolana de Ciências Sociais (Luanda), vol. III, n. ${ }^{\circ}$ 5, Maio de 2013, pp. 81-103 (com Carlos Russo Machado); «Violência urbana e sentimento de insegurança», in J. Bacelar Gouveia (coord.), Estudos de direito e segurança, volume II. Coimbra, Almedina, 2012, pp. 347-366; «Sentimento de insegurança e Estado de Direito: o espectro axial da relação de liberdade e segurança», Segurança e Defesa (Lisboa), n. ${ }^{\circ}$ 17, Abril-Junho de 2011, pp. 70-83; «Global changes and geopolitics of natural ressources», comunicação apresentada na International conference on Ecohydrology and Climate change. Tomar, Portugal, 15-17 de Setembro de 2011; "Changement climatique et géopolitique des ressources en eau», comunicação apresentada ao encontro regional sobre Adaptation aux changements climatiques au Maghreb: Bilan et perspectives. Casablanca, Marrocos, 16-17 de Março de 2010 (com Carlos Russo Machado); «Equity, human security, and environment: key elements of soustainable development», in J. França Martins, L. Rodrigues, T. M. Fernandes (coords.), Cooperar para o desenvolvimento. Oeiras, Instituto Nacional de Administração, 2005, pp. 20-28; L. Noronha, N. Lourenço, J. P. Lobo Ferreira, A. Lleopart, E. Feoli, K. Sawkar, A. Chachadi (eds.), Coastal tourism, environment and sustainable local development. New Delhi, TERI - The Energy Research Institute, 2003.

[e-mail: nelson.lourenco@fcsh.unl.pt]

\section{Carlos Russo Machado}

Licenciado em Geografia pela Faculdade de Letras da Universidade de Lisboa; possui Diploma de Estudos Avançados em Geografia e Planeamento Territorial da Faculdade de Ciências Sociais e Humanas da Universidade Nova de Lisboa (FCSH-UNL). É Director Adjunto do Instituto de Investigação Científica e Tecnológica da Universidade Atlântica e na sua qualidade de Assistente Convidado dessa mesma universidade, aí lecciona as seguintes unidades curriculares: Geografia Física, Introdução ao Ordenamento do Território, Análise de Riscos Ambientais e Geopolítica da Mudança Global. É Assessor Científico do Comité Nacional para o IGBP (International Geosphere-Biosphere Programme) - 
Mudança Global, Assessor Científico da European Alliance of Global Change Research Committees. A sua actividade científica tem-se centrado na problemática da Mudança Global, abrangendo questões como o desenvolvimento de metodologia para análise da interacção sistemas humanos/sistemas naturais, a criação de instrumentos de acompanhamento e de avaliação de impactes de políticas, e na área de construção de sistemas de apoio à decisão. Neste quadro, tem participado em diversos projectos de investigação multidisciplinar, nacionais e internacionais, que têm vindo a ser desenvolvidos em diversos países da União Europeia e da Bacia do Mediterrâneo, Índia, China e América Latina. Publicações recentes: «Global changes and geopolitics of Natural Resources». Proceedings of ЕСОНCC 2011, International Conference on Ecohydrology and Climate Change, Tomar, Portugal, 15-17 de Setembro de 2011 (em parceria com N. Lourenço); «Geotourism routes in urban areas: a preliminary approach to the Lisbon geoheritage survey», GeoJournal of Tourism and Geosites, vol. 8, n. ${ }^{\circ}$ 2, 2011, pp. 281-294 (em parceria com M. L. Rodrigues e E. Freire); "Changement climatique et géopolitique des ressources en eau», Proceedings of rencontre régionale adaptation aux changements climatiques au Maghreb: Bilan et perspectives. Casablanca, Marrocos, 16-17 de Março de 2010 (em parceria com N. Lourenço); "Water resources in Mediterranean Region. Factors ans constraints for improving human well-being in a water stressed region», MGNotícias, n. ${ }^{\circ}$ 10, 2010, pp. 15-18 (em parceria com N. Lourenço); «Order and chaos in landscape: the role of sutability maps to plan sustainable development», Ecological questions. An International Journal on Controversial Problems of Ecology, ${ }^{\circ}{ }^{\circ}$ 8, 2007, pp. 77-86 (em parceria com M. Dragan; M. Duriavig; E. Feoli; M. Fernetti; e N. Lourenço); «Understanding the pattern of Atlantic Forest Fragmentation: preliminary results of exploratory data analysis for an area of the South East of Bahia, Brazil», in Lafortezza R. and Sanesi G. (eds.), Patterns and processes in forest landscape. Consequences of human management, Firenze, Accademia Italiana di Scienze Forestali, 2006, pp. 169-176 (em parceria com M. Duriavig; E. Feoli; e $\mathrm{N}$. Lourenço); The challenge of sustainable ecosystem development in Cachoeira catchment, South Bahia, Brazil, Barcarena, Universidade Atlântica, 2004 (em parceria com C. Reisdorff e M. Duriavig).

[e-mail: cmachado@uatlantica.pt] 